\title{
Microbial P450 enzymes in biotechnology
}

Vlada B. Urlacher, Sabine Lutz-Wahl and Rolf D. Schmid

Institut für Technische Biochemie, Universität Stuttgart

Allmandring 31

D-70569 Stuttgart

Germany

Tel: +49-(0)711-685-3192

Fax: +49-(0)711-685-3196

e-mail: rolf.d.schmid @rus.uni-stuttgart.de

Sabine Lutz-Wahl

Institut für Lebensmitteltechnologie, Fachgebiet Biotechnologie,

Universität Hohenheim

Emil-Wolff Str. 14

D-70599 Stuttgart

Germany 


\begin{abstract}
Oxidations are key reactions in chemical syntheses. Biooxidations using fermentation processes have already conquered some niches in industrial oxidation processes, since they allow the introduction of oxygen even into non-activated carbon atoms in a sterically and optically selective manner which is difficult or impossible to achieve by synthetic organic chemistry. Biooxidation using isolated enzymes is limited to oxidases and dehydrogenases. Surprisingly, cytochrome P450 monooxygenases (CYPs) have scarcely been studied for use in biooxidations, although they are one of the largest known superfamilies of enzyme proteins. Their gene sequences have been identified in various organisms such as humans, bacteria, algae, fungi and plants. The reactions catalyzed by P450s are quite diverse and range from biosynthetic pathways (e.g. those of animal hormones and secondary plant metabolites) to the activation or biodegradation of hydrophobic xenobiotic compounds (e. g. those of various drugs in the liver of higher animals). From a practical point of view, the great potential of P450s is limited by their functional complexity, low activity, and limited stability. In addition, P450-catalyzed reactions require a constant supply of $\mathrm{NAD}(\mathrm{P}) \mathrm{H}$ which makes continuous cell-free processes very expensive. Quite recently, several groups have started to investigate cost-efficient ways which could allow the continuous supply of electrons to the heme iron. These include, for example, the use of electron mediators, direct electron supply from electrodes and enzymatic approaches. In addition, methods of protein design and directed evolution have been applied in an attempt to enhance the activity of the enzymes and improve their selectivity. The promising application of bacterial P450s as catalyzing agents in biocatalytic reactions and recent progress made in this field are covered in this review.
\end{abstract}




\section{Introduction}

Regio- or stereoselective oxidation is a key task of synthetic organic chemists. A hydroxy group can be introduced to an activated carbon atom by a variety of procedures, e. g. by epoxidation/hydrolysis, the addition of water, nucleophilic substitution, reduction, or, if allylic positions are to be oxidized, by radical reactions. However, these reactions are often not stereoselective and do not allow the distinction of carbon atoms carrying the same type of activation among, for example, two double bonds. In addition, the hydroxylation of nonactivated carbon atoms can only be achieved by radical reactions, which are, as a rule, not selective enough to lead to a chiral hydroxy group at the desired position.

Several enzymes catalyze the introduction of an oxygen atom into a substrate molecule. Dioxygenases, peroxidases, oxidases, and dehydrogenases are able to do so in the case of activated carbon atoms. Since most enzymes are regio- and stereospecific, enzymatic oxidations certainly provide an excellent alternative for the organic chemist. The challenge lies in finding a suitable enzyme with the robustness, ease of handling, and the desired regioand stereospecificity. In this context, P450 monooxygenases (“mixed function hydroxylases”) constitute interesting alternatives. They are able to introduce atomic oxygen into allylic positions, double bonds, or even into non-activated C-H bonds. They have been recognized as a major enzyme superfamily which currently contains over 1000 members (http:// www.icgeb.trieste.it/ p450srv/new/p450.html) with a vast repertoire of substrate specificities that can be exploited in biotechnologcal applications. In addition, they can be modified by rational design or directed evolution to accommodate an even wider range of unnatural, synthetic substrates. P450 monooxygenases of the mammalian liver have been found to exhibit extremely wide substrate specificity which is a prerequisite for their ability to activate or detoxify hydrophobic molecules entering the blood stream.

P450 monooxygenases might thus seem the enzyme species of choice for biooxidation. However, some major disadvantages still exist. Most P450 monooxygenases are characterized by low activity, limited stability, need of an expensive cofactor - $\mathrm{NAD}(\mathrm{P}) \mathrm{H}$ to reduce the heme iron and general dependence on auxiliary electron carrier proteins. From a technical point of view, microbial (prokaryotes and unicellular fungi) P450s are easier to handle than P450 enzymes from plants and animals despite sharing most of these disadvantages. They are not membrane-associated and exhibit a relatively high stability. Therefore, the potential of this class of enzymes to be used in biooxidation reactions is currently being investigated and is summarized in this review. 


\section{P450 monooxygenases: whole cell oxidations}

Currently, the use of P450 enzymes in industrial processes is restricted to fermentation. The few technical examples include the biotransformation of steroid hormones, the formation of dicarboxylic acids from alkanes, and the hydroxylation of aromatic synthones. The microbial oxidation involving a P450 monooxygenase is exploited industrially in the 11ß-hydroxylation of Reichstein S, a progesterone derivative which leads to corticosteroids with antiinflammatory activity. In this process fungi of the genus Curvularia are used (Petzoldt et al. 1982). Another example is the total synthesis of pregnenolone from ergosterol by recombinant Saccharomyces cerevisia cells harboring a number of foreign genes including bovine cytochrome P450, adrenodoxin, and adrenodoxin reductase (Duport et al. 1998). Using an industrial yeast strain of Candida tropicalis, engineered for the formation of dicarboxylic acids from alkanes, very high productivity was reported. The productivity of a strain unable to perform beta-oxidation which contains the amplified original P450 monooxygenase and NADH-cytochrome reductase was increased by 130\% (Picataggio et al. 1992). The chemical hydroxylation of aromatic compounds usually leads to the formation of regioisomers. The fungal strain Beauveria bassiana Lu 700 was identified to selectively hydroxylate 2phenoxypropionic acid to 2-(4'-hydroxyphenoxy)propionic acid (Ladner et al. 1995; Dingler et al. 1996) which is used for the synthesis of a number of agrochemicals. This strain has also proved a suitable catalyst for the selective monohydroxylation of other aromatic carboxylic acids. With regard to the industrial degradation of environmental contaminants, the white rot fungus Pleurotus ostreatus was found to be capable of metabolizing phenanthrene to phenanthrene-trans-9,10-dihydrodiol and 2,2-diphenic acid as well as mineralizing it to $\mathrm{CO}_{2}$ as part of the fermentation process (Bezalel et al. 1996).

While all these processes are based on microbial oxidations as a central part of the fermentation processes involving P450 monooxygenase systems, no in vitro system, such as an enzyme reactor, is currently available. Why, one wonders, has this technology not been established yet, and what are its future prospects?

\section{Cytochrome P450 Monooxygenases}

\section{Occurrence}

Cytochrome P450 enzymes are monooxygenases (E.C.1.14.---). It is possible to isolate them 
from bacteria, yeasts, insects, mammalian tissues, and plants (http://drnelson.utmem.edu/CytochromeP450.html). They play an essential role in the biosynthesis of prostaglandins, steroids and numerous secondary metabolites in plants and actinomycetes, as well as in the detoxification of poorly water-soluble compounds such as drugs or chemical pollutants.

Structure and Reaction Mechanism

P450 monooxygenases are heme-containing enzymes. The essential step in the oxidation of a substrate by P450 is the addition of one atom of molecular oxygen, that is activated by a reduced heme iron, to the substrate. The reaction is usually a hydroxylation reaction (Fig. 1). However, P450s which are able to catalyze epoxidation, sulfoxidation, or dealkylation reactions are also known. The second oxygen atom is reduced to water, thereby accepting electrons from $\mathrm{NAD}(\mathrm{P}) \mathrm{H}$ via a flavoprotein or a ferredoxin. The activation of oxygen is common to all P450s. This activation takes place at the iron-protoporphyrin IX (heme). The heme iron is six-fold coordinated. It has a conserved thiolate residue as the fifth ligand and, in the inactive ferric form, a water molecule as its sixth ligand. The catalytic mechanism involves six steps (Fig. 2). (1) First, the substrate is bound and the water molecule is displaced (2). Then the ferric enzyme is reduced to a ferrous state by a one-electron transfer (3). Molecular oxygen is then bound, resulting in a ferrous-dioxy species (4). A second reduction, followed by a proton transfer leads to an iron-hydroperoxo intermediate (5). The cleavage of the O-O bond releases water and an activated iron-oxo ferryl species (6). This iron-oxo ferryl oxidizes the substrate and the product is subsequently released. In a side-pathway, referred to as peroxide shunt, hydrogen peroxide can be employed as a source of both electrons and oxygen (Fig. 2).

The details of the mechanism underlying the unusual substrate diversity of P450s are currently not fully understood. Theoretical studies on the mechanism of P450s and crystallographic data suggest that two successive processes contribute to the catalysis. These involve the formation of an iron-oxo ferryl species (see step 6), followed by monooxygenation of the substrate by this species (Hata et al. 2001). The properties of the iron-oxo ferryl species - the last active Fe-intermediate in the catalytic cycle - are still poorly understood although the crystal structure of this species was recently identified (Schlichting et al. 2000). 
Depending on their redox partners, P450 enzyme systems can be divided into four classes. Most bacterial monooxygenases belong to class I and require an FAD-containing reductase and an iron sulfur redoxin (P450cam). Class II enzymes, which are mostly attached to the endoplasmatic reticulum, only require an FAD/FMN-containing P450 reductase for the transfer of electrons. This electron transport system is located in microsomes. The P450 enzymes from Bacillus megaterium (CYP102A1) (below referred to as P450 BM-3) (Li and Poulos 1999), Bacillus subtilis (CYP102A2) (Lee et al. 2001) and Fusarium oxysporum (CYP505) (Kitazume et al. 2000) also belong to this class of enzymes. They are self-sufficient enzymes containing the P450 monooxygenase and the FAD/FMN-reductase domain on a single peptide chain. Class III enzymes do not require electron donors. These self-sufficient enzymes convert peroxygenated substrates which already contain oxygen. P450s from class IV receive their electrons directly from NAD(P)H. Only one representative of this class has been described so far (P450nor) (Nakahara et al. 1994).

The structures of P450s were determined by X-ray crystallography at high resolution (Poulos et al. 1986; Hasemann et al. 1994; Nakahara et al. 1994; Cupp-Vickery and Poulos 1995; Li and Poulos 1997; Park et al. 2000; Williams et al. 2000a; Podust et al. 2001; Podust et al. 2003; Yano et al. 2003). The structure of all enzymes resolved so far is very similar despite the low amino-acid sequence identity of $<20 \%$ (Graham and Peterson 1999). Their tertiary structure is usually composed of $13 \alpha$-helixes and $5 \beta$-sheets. The area around the heme group is structurally conserved and reflects a common mechanism of electron transfer and oxygen activation. The conserved region is formed by a four-helix bundle (D, E, I and L), helix J, helix K, and two sets of $\beta$-sheets ( $\beta 1$ and $\beta 2$ ) (Peterson 1998). Nine of the ten examined cytochrome P450s are water-soluble proteins. Eukaryotic cytochrome P450s are membraneassociated proteins that are more difficult to crystallize. So far, only the X-ray structures of two membrane-bound mammalian P450s - CYP2C5 and CYP2C9 - have been determined (Williams et al. 2000b). Models of other mammalian P450s are based on the structure of CYP2C5 and its bacterial analogues (Dai et al. 1998; Bathelt et al. 2002).

Production and Purification

Bacterial P450 monooxygenases can efficiently be expressed in Escherichia coli cells. All microbial P450 monooxygenases that are expressed in E. coli keep their activity during production and isolation. They yield 30-50 mg of active protein per liter in standard batch 
processes (Oster et al. 1991; Bell et al. 2001; Yano et al. 2003). In some cases, the expression depends on the addition of the heme precursor aminolevulinic acid (Schwaneberg et al. 2001). Expensive isopropyl-beta-D-thiogalactopyranoside (IPTG) is often used as an inducer in $E$. coli expression systems that are based on the lac repressor. However, lactose can be also used as substitute (Woyski and Cupp-Vickery 2001).

Purification usually involves the combination of ammonium sulfate precipitation, subsequent ion-exchange chromatography, and gel filtration or hydrophobic interaction (Miles et al. 1992; Munro et al. 1996); (McLean et al. 2002). Alternatively, affinity chromatography on 2'5'-ADP-Sepharose can be used which has proven most successful with fusion proteins such as P450 BM-3 (Black et al. 1994). This method is very efficient though expensive. It has been shown that the costs can be reduced by using 2',3'-adenosine monophosphate instead of 2'adenosine monophosphate as eluting agent (Rock and Jones 2001). A successful alternative for the laboratory-scale purification of P450s is metal-ion affinity chromatography using $\mathrm{His}_{6}$ tagged proteins (Delcarte et al. 2003; Maurer et al. 2003). However, both approaches described above, are either time-consuming or expensive and thus not suitable for the gramscale purification of P450 monooxygenase. Therefore, a fast and cheap one-step purification protocol for P450 BM-3 that is based on commercial anion exchangers (DEAE 650M, SuperQ $650 \mathrm{M}$ ) was developed. It yields 79-86 \% recovery and 86-90\% purity (Schwaneberg et al. 1999a).

Immobilization

The relatively poor stability of P450 monooxygenases and the costs of product separation still impede the technical application of these enzymes (Urlacher and Schmid 2002). Immobilization of enzymes has proven useful for in vitro biotransformations. It renders the enzymes stable for operation and storage (Tischer and Wedekind 1999) and allows simple product separation. So far, only few mammalian P450s have been immobilized (FernandezSalguero et al. 1993; Koebe et al. 1994a; Koebe et al. 1994b), and reports on the immobilization of microbial P450 enzymes are rare. The first studies on the immobilization of a P450 enzyme from Saccharomyces cerevisiae were based on microsomal fractions (Azari and Wiseman 1982) or permeabilized cells (King et al. 1988). Permeabilized yeast cells were entrapped in calcium alginate and the authors report a significant stabilization effect of the immobilization: the residual activity was 35\% after two weeks and 20\% after four weeks. The 
entrapment of the microsomal fraction of S. cerevisiae cells in calcium alginate gel, however, was much more successful. Immobilized microsomes still retained $84 \%$ of their activity after two weeks and $60 \%$ after four weeks. Highly purified cytochrome P450 from S. cerevisiae was also successfully immobilized by entrapment in alginate. It exhibited a stability similar to that of permeabilized cells but inferior to that of the microsomal fractions (45\% activity after 2 weeks and $15 \%$ after 4 weeks). Purified yeast monooxygenase and reductase were also successfully immobilized to BrCN-activated Sepharose 4B with 100\% retention and $70 \%$ activity after two and 58\% after 4 weeks.

A procaryotic P450 enzyme from Streptomyces griseus (CYP105D1) was immobilized on the ionic exchange matrix DE52 with 85\% retention. No significant loss of activity has been observed during one day of reaction at $25^{\circ} \mathrm{C}$ with co-factor recycling (Taylor et al. 2000). The immobilized CYP105D1 showed a reduced turnover of the substrates benzo[a]pyrene $(0,17 / \mathrm{min}$ compared to $0,34 / \mathrm{min}$ with the free enzyme) and warfarin $(0,9 / \mathrm{min}$ compared to 3,0/min). In the presence of an NADPH recycling system, the accumulation of 4'hydroxywarfarin was observed even after 38 hours, and yields reached $38,8 \mathrm{nmol}$ at $25^{\circ} \mathrm{C}$.

Maurer et al. were able to show that P450 BM-3 from Bacillus megaterium binds firmly to anion exchangers such as DEAE and SuperQ (Maurer et al. 2003). However, the products of the reaction also adsorbed to these matrices. Thus, DEAE and SuperQ are unsuitable for biotechnical purposes. In addition, washes with higher ionic strength leached the enzyme from the carrier. The enzyme was unable to adsorb on celite, a porous silicate matrix derived from diatomaceous soil (Maurer et al. 2003). Immobilization of two P450 BM-3 mutants was further examined using a sol-gel matrix derived from tetraethoxyorthosilicate (TEOS) (Gill 2001). This approach resulted in an enzyme that displayed long-term activity (half-life of 30 days at $25^{\circ} \mathrm{C}$ ), providing the opportunity to convert a large variety of substrates.

\section{Cofactor Regeneration}

A key issue in the use of isolated P450s in biotechnology is the demand for the continuous electron supply required by the heme iron. In vivo, the electrons are supplied by the generation of $\mathrm{NAD}(\mathrm{P}) \mathrm{H}$ which is, however, far too expensive to be used in equimolar concentrations during technical applications. Direct electron supply from electrodes (Kazlauskaite et al. 1996), use of electron mediators (Schwaneberg et al. 2000), as well as enzymatic (Fernandez-Salguero et al. 1993; Taylor et al. 2000) and organometallic (Hollmann et al. 2002) approaches have been suggested as sources of the required reduction equivalents. 
Direct chemical reduction of the heme iron is very inefficient. During the hydroxylation of palmitic acid by P450 BM-3, for example, the reduction of oxygen in the presence of sodium dithionite was at least 8000 times lower compared to that of NADPH (Fang et al. 1996).

The direct electron transfer from carbon-based electrodes to P450cam - from Pseudomonas putida (CYP101) (in the following referred to as P450cam) - was demonstrated (Kazlauskaite et al. 1996). However, direct electrochemistry of P450s immobilized on a cathode is complicated because of the deeply buried heme-iron and the instability of the enzyme upon interaction with the electrode surface. Recent improvements include the modification of the electrode surface and/or the use of mediators which assist in the catalytic cycle. So, a bioelectrochemical reactor was constructed where a continuous catalytic cycle from the cathode to P450cam via its natural redox partner - putidaredoxin led to a nearly stoichiometric conversion of camphor (Reipa et al. 1997). Artificial redox partners can also assist in the electron transport between electrode and monooxygenase. An artificial redox chain was assembled in a chimeric fusion protein using the heme domain of P450 BM-3 and flavodoxin from Desulfovibrio vulgaris connected by a natural loop of P450 BM-3 reductase (Gilardi et al. 2002). The electron transfer between working electrode and the monooxygenase part of the chimera takes place over the flavodoxin part. P450cam which was immobilized on a glassy carbon electrode modified with sodium montmorillonite exhibited reversible redox behavior (Lei et al. 2000). Direct electron transfer was reported for several oxygenases that were immobilized on lipid-modified pyrolytic graphite electrodes (Zhang et al. 2002). A Co(III) sepulchrate mediator and Pt electrodes were able to transfer electrons to six different P450 monooxygenases (Estabrook et al. 1996a; Estabrook et al. 1996b; Estabrook et al. 1996c). However, the conversion rates in these systems were at least eight-fold lower compared to when NADPH was used. Figure 3 illustrates a system based on Co(III)sepulchrate and zinc dust as electron donor that was recently developed (Schwaneberg et al. 1999b). The turnover reached $20 \%$ of the activity in the presence of NADPH. In contrast to direct electrochemical approaches, this activity is over $75 \%$ higher.

The electrochemical regeneration of expensive $\mathrm{NAD}(\mathrm{P}) \mathrm{H}$ is usually limited by the side reactions that are generated by high overpotentials. To avoid or reduce the effect of these side reactions pentamethylcyclopentadienyl rhodium bipyridine complex was employed successfully (Hollmann et al. 2002).

A popular idea with regard to $\mathrm{NAD}(\mathrm{P}) \mathrm{H}$ regeneration is the use of a second, coupled enzyme such as a dehydrogenase. This approach has already led to the wider use of redox enzymes for chemical synthesis (Hummel and Kula 1989; Seelbach et al. 1996). The regeneration of the 
cofactor requires a second enzyme and a second substrate. Therefore, a second product is also generated which must be separated from the desired end product. Formate dehydrogenase (FDH) has turned out to be a profitable option that is also of advantage due to its commercial applications. This enzyme catalyses the oxidation of formate anions to carbon dioxide with the concomitant reduction of $\mathrm{NAD}^{+}$to $\mathrm{NADH}$. The advantage of FDH is the low cost of formate and the simple removal of the reaction product $\mathrm{CO}_{2}$. Unfortunately, formate dehydrogenases are $\mathrm{NAD}^{+}$-dependent enzymes, but most P450s depend on NADPH. An FDH mutant from Pseudomonas sp. 101 was recently engineered which exhibits high activity towards NADP ${ }^{+}$(Tishkov et al. 1999), enabling it to be used as NADPH-regenerating enzyme in combination with P450 BM-3 (Fig. 4) (Maurer et al. 2003). A further approach to overcome the problem of cofactor costs is the use of the peroxide shunt pathway with strong oxidants such as hydrogen peroxide or periodate which directly catalyze the reduction of the heme-iron (Naqui et al. 1986; Coon et al. 1996). This method is, however, associated with the problem of fast inactivation of the enzyme. However, directed evolution has been successfully applied to evolve the heme domains of P450cam and P450 BM-3 to enhance the efficiency of the "peroxide shunt” pathway (Joo et al. 1999; Cirino and Arnold 2002).

\section{Assays for P450 Monooxygenases}

Traditionally, three types of activity assays are used for the investigation of P450 activity: (1) radiolabeling of substrates (Miura and Fulco 1975); (2) the use of fluorogenic substrates such as 7-ethoxyresorufin (Klotz et al. 1984), 7-ethoxycoumarin (Aitio 1978) and their derivatives (DeLuca et al. 1988; Sone et al. 1989) with subsequent separation of the products on HPLC; and (3) GC/GC-MS analysis of the products (Capdevila et al. 1996; Li et al. 2001a). Unfortunately, not all of these methods can be adopted for high-throughput screening which is a fundamental prerequisite for techniques of directed evolution required for P450 improvement. Methods of directed evolution, applied on enzyme lead to creation of several thousand different mutants, which should be screened for improved activity or changed specificity.

For screening mutant libraries of the P450 enzymes the monitoring of $\mathrm{NAD}(\mathrm{P}) \mathrm{H}$ consumption during substrate oxidation is usually used (Boddupalli et al. 1990; Appel et al. 2001; Lentz et al. 2001). The modification of this method, so-called "alkali assay”, was developed and adapted to the microtiterplate scale, and employed in high throughput screening (HTS) (Tsotsou et al. 2002). Mutants of P450 BM-3 were tested with different substrates and their 
activities were measured by detection of the alkaline products of NAD(P)H-oxidation. The alkali assay is not substrate specific and can thus be applied to testing substrate mixtures.

A rapid direct assay for P450 BM-3 and related enzymes is based on the hydroxylation of a surrogate substrate, para-nitrophenoxycarboxylic acids, to $\omega$-oxycarboxylic acid and paranitrophenolate (Schwaneberg et al. 1999b). The kinetics of para-nitrophenolate formation can be measured directly at $410 \mathrm{~nm}$. After permeabilization of E. coli cells producing a recombinant P450 enzyme, the time-consuming step of cell lysis could be avoided as could the re-suspension and centrifugation procedures (Schwaneberg et al. 2001). This assay allows screening of thousands of samples and can be adopted for HTS.

\section{Protein Engineering of P450 Monooxygenases}

Protein engineering is generally defined as modification of enzyme by rational design or directed evolution with the aim of altering their properties. Rational design of enzyme through site-directed mutagenesis requires a solid structural basis and an understanding of its catalytic mechanism. Directed evolution in contrast does not need any structural information and involves either random mutagenesis (e.g. error-prone PCR) or recombination of gene fragments (e.g. gene shuffling, staggered extension process etc.)

The structures that are available for several P450 enzymes allow for the rational design of proteins, which provides important information on the role of the most important amino acids in the binding pocket. Detailed studies have been undertaken to elucidate the cytochrome P450 monooxygenase from Pseudomonas putida (CYP101) - P450cam which is a camphorhydroxylating enzyme (Atkins and Sligar 1988a; Atkins and Sligar 1988b; Atkins and Sligar 1990; Bell et al. 2001; Bell et al. 2003a). It was shown that mutations of the active site residue Y96 into more hydrophobic residues considerably increased the activity of P450cam towards the oxidation of hydrophobic molecules smaller than camphor, such as styrenes (Stevenson et al. 1996; Nickerson et al. 1997), or larger than camphor, such as naphthalene and pyrene (England et al. 1998; Harford-Cross et al. 2000). A double mutant of P450cam (F87 and Y96) exhibited enhanced oxidation of the polycyclic aromatic hydrocarbons phenantrene, fluoranthene, pyrene, and benzo[a]pyrene (Harford-Cross et al. 2000). Engineered P450cam is able to oxidize very small substrates which are completely different from the natural camphor substrate. Mutant F87W/Y96F/T101L/V247L, for example, oxidized butane with a turnover rate of $750 \mathrm{~min}^{-1}$ (Bell et al. 2002). 
Based on docking experiments with camphor and pinene P450cam was engineered such that it exhibited enhanced activity towards $(+)$ - $\alpha$-pinene. Crystallization of the most selective mutant and investigation of substrate movements within the binding pocket provided additional information that was required for constructing the highly specific mutant. The products (+)cis-verbenol and (+)-verbenone obtained are natural fragrances and flavors (Bell et al. 2003b). Studies have also been carried out using P450 BM-3 from Bacillus megaterium (CYP102A1) - P450 BM-3. This monooxygenase contains a long hydrophobic substrate channel. Its natural substrates include saturated and unsaturated fatty acids of a chain length of C12-C20. The analysis of the structure and the comparison of substrate-bound and substrate-free forms revealed the importance of the Y51 and R47 residues at the entrance of the substrate channel. The mutation of these and additional amino acids alters the enzyme's specificity (Carmichael and Wong 2001; Cowart et al. 2001). However, the substitution of either R47 or Y51 alone did not lead to an observable effect on substrate binding affinity and activity (Li and Poulos 1999). NMR studies and experiments proved that a single mutation at residue F87 changed the regiospecificity of the hydroxylation process (Oliver et al. 1997). In contrast to the wildtype enzyme, which only catalyzes the hydroxylation at the $\omega-1, \omega-2$, and $\omega-3$ position, the mutant is able to catalyze the hydroxylation of fatty acids at the $\omega$ position. Other mutants that are substituted at the same position can also convert cytochrome P450 BM-3 into a regio- and stereoselective $(14 S, 15 R)$-arachidonic acid epoxygenase (Graham-Lorence et al. 1997) or into a highly enantioselective 3-chlorostyrene epoxygenase (Li et al. 2001a).

In a process called "rational evolution" (i.e., protein design combined with directed evolution) it was possible to shift the substrate specificity of P450 BM-3 from C-12 fatty acids to C-10 and C-8 in the fatty acid pseudosubstrates 10- and 8-p-nitrophenoxycarboxylic acid (Lentz et al. 2001). A triple mutant (A74G/F87V/L188Q) was able to hydroxylate indole (Appel et al. 2001) and also a wide range of other substrates that virtually do not have any resemblance to fatty acids which are regarded as the natural substrate of P450 BM-3. Thus, naphthalene (a polycyclic aromatic hydrocarbon), n-octane (an n-alkane), and 8-methylquinoline (a heteroarene) were oxidized. The acceptance of a wide variety of substrates compares well with the wide substrate specificity observed in some eukaryotic P450s (e. g. those in mammalian liver). This wide substrate spectrum certainly provides exploitable opportunities for chemical synthesis as well as in the industrial degradation of environmental contaminants. A key finding in the latter area was the oxidation of polycyclic aromatic hydrocarbons (PAHs) (Carmichael and Wong 2001; Li et al. 2001b). Three amino acid substitutions in P450 BM-3 (R47L/Y51F/A264G) led to an up to 200-fold increase in the activity of this enzyme to 
PAHs such as phenanthrene, fluoranthene and pyrene. The observation that the mutant A74G/F87V/L188Q is highly active with regard to the oxidation of other PAHs such as naphthalene, fluorine, acenaphthene, acenaphthalene, and 9-methylanthracene suggested that the reaction is based on improved hydrophobic interactions via Ala74 and Leu188 (Li et al. 2001b).

Methods of directed evolution have become a powerful tool for improving the utility of enzymes for industrial application generally and proved to be very efficient in improving the enzymatic activity of P450 BM-3 and in broadening its substrate specificity. Arnold and colleagues, for example, succeeded in increasing the activity of P450 BM-3 towards the saturated hydrocarbon octane (Farinas 2001) and even the gaseous alkane propane (Glieder et al. 2002). Some mutants were found which lead to either the (R)- or (S)-enantiomer products of alkane hydroxylation (Peters et al. 2003).

Using error-prone PCR some mutants of P450cam (Joo et al. 1999) and P450 BM-3 (Cirino and Arnold 2003) were created, which demonstrate high activity with hydrogen peroxide, which acts as both an oxidant and an electron donor, thereby substituting NAD(P)H.

\section{Concluding remarks}

Cytochrome P450 enzymes are maturing as industrially useful biocatalysts. Although recent developments in this field provide new perspectives with respect to exploiting the P450 monooxygenases in biotechnical applications, many unresolved issues remain. Further work should be focused on key aspects such as operational stability of the P450s and cofactor regeneration during biocatalysis. A combination of chemical, electrochemical, physical and biological approaches will contribute to answer these important questions. 


\section{References}

Aitio A (1978) A simple and sensitive assay of 7-ethoxycoumarin deethylation. Anal Biochem 85: 488-491

Appel D, Lutz-Wahl S, Fischer P, Schwaneberg U, Schmid RD (2001) A P450 BM-3 mutant hydroxylates alkanes, cycloalkanes, arenes and heteroarenes. J Biotechnol 88: 167-171

Atkins WM, Sligar SG (1988a) Deuterium isotope effects in norcamphor metabolism by cytochrome P-450cam: kinetic evidence for the two-electron reduction of a high-valent iron-oxo intermediate. Biochemistry 27: 1610-1616

Atkins WM, Sligar SG (1988b) The roles of active site hydrogen bonding in cytochrome P450cam as revealed by site-directed mutagenesis. J Biol Chem 263: 18842-18849

Atkins WM, Sligar SG (1990) Tyrosine-96 as a natural spectroscopic probe of the cytochrome P-450cam active site. Biochemistry 29: 1271-1275

Azari MR, Wiseman A (1980) Solubilization of Cytochrome P450 in a high yield from Saccharomyces cerivisiae microsomal membrane: stabilization effect. Biochem Soc Trans 8: 713-714

Bathelt C, Schmid RD, Pleiss J (2002) Regioselectivity of CYP2B6: homology modeling, molecular dynamics simulation, docking. J Mol Model (Online) 8: 327-335

Bell SG, Harford-Cross CF, Wong LL (2001) Engineering the CYP101 system for in vivo oxidation of unnatural substrates. Protein Eng 14: 797-802

Bell SG, Stevenson JA, Boyd HD, Campbell S, Riddle AD, Orton EL, Wong LL (2002) Butane and propane oxidation by engineered cytochrome P450cam. Chem Commun (Camb)490-491

Bell SG, Chen X, Xu F, Rao Z, Wong LL (2003a) Engineering substrate recognition in catalysis by cytochrome P450cam. Biochem Soc Trans 31: 558-562

Bell SG, Chen X, Sowden RJ, Xu F, Williams JN, Wong LL, Rao Z (2003b) Molecular recognition in (+)-alpha-pinene oxidation by cytochrome P450cam. J Am Chem Soc 125: 705-714

Bezalel L, Hadar Y, Fu PP, Freeman JP, Cerniglia CE (1996) Metabolism of phenanthrene by the white rot fungus Pleurotus ostreatus. Appl Environ Microbiol 62: 2547-2553

Black SD, Linger MH, Freck LC, Kazemi S, Galbraith JA (1994) Affinity isolation and characterization of cytochrome P450 102 (BM-3) from barbiturate-induced Bacillus megaterium. Arch Biochem Biophys 310: 126-133

Boddupalli SS, Estabrook RW, Peterson JA (1990) Fatty acid monooxygenation by cytochrome P-450BM-3. J Biol Chem 265: 4233-4239

Capdevila JH, Wei S, Helvig C, Falck JR, Belosludtsev Y, Truan G, Graham-Lorence SE, Peterson JA (1996) The highly stereoselective oxidation of polyunsaturated fatty acids by cytochrome P450BM-3. J Biol Chem 271: 22663-22671

Carmichael AB, Wong LL (2001) Protein engineering of Bacillus megaterium CYP102.The oxidation of polycyclic aromatic hydrocarbons. Eur J Biochem 268: 3117-3125

Cirino PC, Arnold FH (2002) Regioselectivity and activity of cytochrome P450 BM-3 and mutant F87A in reactions driven by hydrogen peroxide. Advanced Synthesis \& Catalysis 344: 932-937

Cirino PC, Arnold FH (2003) A Self-Sufficient Peroxide-Driven Hydroxylation Biocatalyst. Angew Chem Int Ed Engl 42: 3299-3301

Coon MJ, Vaz AD, Bestervelt LL (1996) Cytochrome P450 2: peroxidative reactions of diversozymes. Faseb J. 10: 428-434

Cowart LA, Falck JR, Capdevila JH (2001) Structural determinants of active site binding affinity and metabolism by cytochrome P450 BM-3. Arch Biochem Biophys 387: 117124 
Cupp-Vickery JR, Poulos TL (1995) Structure of cytochrome P450eryF involved in erythromycin biosynthesis. Nat Struct Biol 2: 144-153

Dai R, Pincus MR, Friedman FK (1998) Molecular modeling of cytochrome P450 2B1: mode of membrane insertion and substrate specificity. J Protein Chem 17: 121-129

Delcarte J, Fauconnier ML, Jacques P, Matsui K, Thonart P, Marlier M (2003) Optimisation of expression and immobilized metal ion affinity chromatographic purification of recombinant (His)(6)-tagged cytochrome P450 hydroperoxide lyase in Escherichia coli. J Chromatogr B Analyt Technol Biomed Life Sci 786: 229-236

DeLuca JG, Dysart GR, Rasnick D, Bradley MO (1988) A direct, highly sensitive assay for cytochrome P-450 catalyzed O-deethylation using a novel coumarin analog. Biochem Pharmacol 37: 1731-1739

Dingler C, Ladner W, Krei G, Cooper B, Hauer B (1996) Preparation of (R)-2-(4hydroxyphenoxypropionic acid by biotransformation. Pestic. Sci. 46: 33-35

Duport C, Spagnoli R, Degryse E, Pompon D (1998) Self-sufficient biosynthesis of pregnenolone and progesterone in engineered yeast. Nat Biotechnol 16: 186-189

England PA, Harford-Cross CF, Stevenson JA, Rouch DA, Wong LL (1998) The oxidation of naphthalene and pyrene by cytochrome P450cam. FEBS Lett 424: 271-274

Estabrook RW, Shet MS, Faulkner KM, Fisher CW (1996a) The use of electrochemistry for the synthesis of 17 alpha-hydroxyprogesterone by a fusion protein containing P450c17. Endocr. res. 22: 665-671

Estabrook RW, Shet MS, Fisher CW, Jenkins CM, Waterman MR (1996b) The interaction of NADPH-P450 reductase with P450: an electrochemical study of the role of the flavin mononucleotide-binding domain. Arch. Biochem. Biophys. 333: 308-315

Estabrook RW, Faulkner KM, Shet MS, Fisher CW (1996c) Applications of electrochemistry for P450-catalyzed reactions. Methods Enzymol. 272: 44-51

Fang X, Halpert, R. J (1996) Dithionite-supported hydroxylation of palmitic acid by cytochrome P450 BM-3. Drug Metab. Dispos. 24: 1282-1285

Farinas ET, Schwaneberg, U., Glieder, A., Arnold, F.H. (2001) Directed evolution of a cytochrome P450 monooxygenase for alkane oxidation. Advanced synthesis and catalysis 343(6+7): 601-606

Fernandez-Salguero P, Gutierrez-Merino C, Bunch AW (1993) Effect of immobilization on the activity of rat hepatic microsomal cytochrome P450 enzymes. Enzyme Microb Technol 15: 100-104

Gilardi G, Meharenna YT, Tsotsou GE, Sadeghi SJ, Fairhead M, Giannini S (2002) Molecular Lego: design of molecular assemblies of P450 enzymes for nanobiotechnology. Biosens Bioelectron 17: 133-145.

Gill I (2001) Bio-doped Nanocomposite Polymers: Sol-Gel Bioencapsulates. Chem Mater 13: 3404-3421

Glieder A, Farinas ET, Arnold FH (2002) Laboratory evolution of a soluble, self-sufficient, highly active alkane hydroxylase. Nat Biotechnol 20: 1135-1139

Graham SE, Peterson JA (1999) How similar are P450s and what can their differences teach us. Arch. Biophys. Biochem. 369: 24-29

Graham-Lorence S, Truan G, Peterson JA, Falck JR, Wei S, Helvig C, Capdevila JH (1997) An active site substitution, F87V, converts cytochrome P450 BM-3 into a regio- and stereoselective (14S,15R)-arachidonic acid epoxygenase. J Biol Chem 272: 1127-1135

Harford-Cross CF, Carmichael AB, Allan FK, England PA, Rouch DA, Wong L-L (2000) Protein engineering of cytochrome P450cam (CYP101) for the oxidation of polycyclic aromatic hydrocarbons. Prot. Eng. 13: 121-128

Hasemann CA, Ravichandran KG, Peterson JA, Deisenhofer J (1994) Crystal structure and refinement of cytochrome P450terp at 2.3 A resolution. J Mol Biol 236: 1169-1185. 
Hata M, Hirano Y, Hoshino T, Tsuda M (2001) Monooxygenation mechanism by cytochrome P-450. J Am Chem Soc 123: 6410-6416

Hollmann F, Witholt B, Schmid A (2002) [cp*Rh(bpy)(H2O)]2+: a versatile tool for efficient and non-enzymatic regeneration of nicotinamide and flavin coenzymes. J Mol Cat B 791: $1-10$

Hummel W, Kula M-R (1989) Dehydrogenases for the synthesis of chiral compounds. Eur. J. Biochem. 184: 1-13

Joo H, Lin Z, Arnold FH (1999) Laboratory evolution of peroxide-mediated cytochrome P450 hydroxylation. Nature 399: 670-673

Kazlauskaite J, Westlake ACG, Wong L-L, Hill HAO (1996) Direct electrochemistry of of Cytochrome P450cam. Chem Commun 18: 2189-2190

King DL, Azari MR, Wiseman A (1988) Immobilization of cytochrome P-450 enzyme from Saccharomyces cerevisiae. Methods Enzymol. 137: 675-686

Kitazume T, Takaya N, Nakayama N, Shoun H (2000) Fusarium oxysporum fatty-acid subterminal hydroxylase (CYP505) is a membrane-bound eukaryotic counterpart of Bacillus megaterium cytochrome P450BM3. J Biol Chem 275: 39734-39740

Klotz AV, Stegeman JJ, Walsh C (1984) An alternative 7-ethoxyresorufin O-deethylase activity assay: a continuous visible spectrophotometric method for measurement of cytochrome P-450 monooxygenase activity. Anal Biochem 140: 138-145

Koebe HG, Pahernik S, Eyer P, Schildberg FW (1994a) Collagen gel immobilization: a useful cell culture technique for long-term metabolic studies on human hepatocytes. Xenobiotica 24: $95-107$

Koebe HG, Wick M, Cramer U, Lange V, Schildberg FW (1994b) Collagen gel immobilisation provides a suitable cell matrix for long term human hepatocyte cultures in hybrid reactors. Int J Artif Organs 17: 95-106

Ladner W, Staudenmaier HR, Hauer B, Müller U, Pressler U, Meyer J, Siegel H (1999). Process for the hydroxylation of aromatic acids using strains of the fungus Beauveria. US Patent, 5,928,912

Lee TR, Hsu HP, Shaw GC (2001) Transcriptional regulation of the Bacillus subtilis bscRCYP102A3 operon by the BscR repressor and differential induction of cytochrome CYP102A3 expression by oleic acid and palmitate. J Biochem (Tokyo) 130: 569-574

Lei C, Wollenberger U, Jung C, Scheller FW (2000) Clay-bridged electron transfer between cytochrome p450(cam) and electrode. Biochem Biophys Res Commun 268: 740-744

Lentz O, Li Q-S, Schwaneberg U, Lutz-Wahl, S., Fischer, P., Schmid, R.D. (2001) Modification of the fatty acid specificity of cytochrome P450BM-3 from Bacillus megaterium by directed evolution: a validated assay. Journal of molecular catalysis B: Enzymatic 15: 123-133

Li H, Poulos TL (1997) The structure of the cytochrome p450BM-3 haem domain complexed with the fatty acid substrate, palmitoleic acid. Nat Struct Biol 4: 140-146

Li H, Poulos TL (1999) Fatty acid metabolism, conformational change, and electron transfer in cytochrome P-450(BM-3). Biochim Biophys Acta 1441: 141-149

Li QS, Ogawa J, Schmid RD, Shimizu S (2001a) Residue size at position 87 of cytochrome P450 BM-3 determines its stereoselectivity in propylbenzene and 3-chlorostyrene oxidation. FEBS Lett 508: 249-252

Li QS, Ogawa J, Schmid RD, Shimizu S (2001b) Engineering cytochrome P450 BM-3 for oxidation of polycyclic aromatic hydrocarbons. Appl Environ Microbiol 67: 5735-5739

Maurer SC, Schulze H, Schmid RD, Urlacher V (2003) Immobilisation of P450BM-3 and an $\mathrm{NADP}(+)$ cofactor recycling system: Towards a technical application of heme-containing monooxygenases in fine chemical synthesis. Advanced Synthesis \& Catalysis 345: 802810 
McLean KJ, Cheesman MR, Rivers SL, Richmond A, Leys D, Chapman SK, Reid GA, Price NC, Kelly SM, Clarkson J, Smith WE, Munro AW (2002) Expression, purification and spectroscopic characterization of the cytochrome P450 CYP121 from Mycobacterium tuberculosis. J Inorg Biochem 91: 527-541

Miles JS, Munro AW, Rospendowski BN, Smith WE, McKnight J, Thomson AJ (1992) Domains of the catalytically self-sufficient cytochrome P-450 BM-3. Genetic construction, overexpression, purification and spectroscopic characterization. Biochem J 288 ( Pt 2): 503-509

Miura Y, Fulco AJ (1975) Omega-1, Omega-2 and Omega-3 hydroxylation of long-chain fatty acids, amides and alcohols by a soluble enzyme system from Bacillus megaterium. Biochim Biophys Acta 388: 305-317

Munro AW, Daff S, Coggins JR, Lindsay JG, Chapman SK (1996) Probing electron transfer in flavocytochrome P-450 BM3 and its component domains. Eur J Biochem 239: 403409

Nakahara K, Shoun H, Adachi S, Iizuka T, Shiro Y (1994) Crystallization and preliminary Xray diffraction studies of nitric oxide reductase cytochrome P450nor from Fusarium oxysporum. J Mol Biol 239: 158-159

Naqui A, Chance B, Cadenas E (1986) Reactive oxygen intermediates in biochemistry. Ann. rev. Biochem. 55: 137-166

Nickerson DP, Harford-Cross CF, Fulcher SR, Wong LL (1997) The catalytic activity of cytochrome P450cam towards styrene oxidation is increased by site-specific mutagenesis. FEBS Lett 405: 153-156

Oliver CF, Modi S, Sutcliffe MJ, Primrose WU, Lian LY, Roberts GC (1997) A single mutation in cytochrome P450 BM3 changes substrate orientation in a catalytic intermediate and the regiospecificity of hydroxylation. Biochemistry 36: 1567-1572

Oster T, Boddupalli SS, Peterson JA (1991) Expression, purification, and properties of the flavoprotein domain of cytochrome P-450BM-3. Evidence for the importance of the amino-terminal region for FMN binding. J Biol Chem 266: 22718-22725

Park SY, Yamane K, Adachi S, Shiro Y, Weiss KE, Sligar SG (2000) Crystallization and preliminary X-ray diffraction analysis of a cytochrome P450 (CYP119) from Sulfolobus solfataricus. Acta Crystallogr D Biol Crystallogr 56: 1173-1175

Peters MW, Meinhold P, Glieder A, Arnold FH (2003) Regio- and Enantioselective Alkane Hydroxylation with Engineered Cytochromes P450 BM-3. J Am Chem Soc 125: 1344213450

Peterson JA, Graham, SE (1998) A close family resemblance: the importance of structure in understanding cytochromes P450. Structure 6: 1079-1085

Petzoldt K, Annen K, Laurent H, Wiechert R (1982) Process for the preparation of 11-betahydroxy steroids. US Patent 4,353,985

Picataggio S, Rohrer T, Deanda K, Lanning D, Reynolds R, Mielenz J, Eirich LD (1992) Metabolic engineering of Candida tropicalis for the production of long-chain dicarboxylic acids. Biotechnology (N Y) 10: 894-898

Podust LM, Poulos TL, Waterman MR (2001) Crystal structure of cytochrome P450 14alpha -sterol demethylase (CYP51) from Mycobacterium tuberculosis in complex with azole inhibitors. Proc Natl Acad Sci U S A 98: 3068-3073

Podust LM, Kim Y, Arase M, Neely BA, Beck BJ, Bach H, Sherman DH, Lamb DC, Kelly SL, Waterman MR (2003) The 1.92-A structure of Streptomyces coelicolor A3(2) CYP154C1. A new monooxygenase that functionalizes macrolide ring systems. J Biol Chem 278: 12214-12221

Poulos TL, Finzel BC, Howard AJ (1986) Crystal structure of substrate-free Pseudomonas putida cytochrome P-450. Biochemistry 25: 5314-5322 
Reipa V, Mayhew MP, Vilker VL (1997) A direct electrode-driven P450 cycle for biocatalysis. Proc Natl Acad Sci U S A 94: 13554-13558

Rock D, Jones JP (2001) Inexpensive purification of P450 reductase and other proteins using 2',5'-adenosine diphosphate agarose affinity columns. Protein Expr Purif 22: 82-83

Schlichting I, Berendzen J, Chu K, Stock AM, Maves SA, Benson DE, Sweet RM, Ringe D, Petsko GA, Sligar SG (2000) The catalytic pathway of cytochrome p450cam at atomic resolution. Science 287: 1615-1622

Schwaneberg U, Sprauer A, Schmidt-Dannert C, Schmid RD (1999a) P450 monooxygenase in biotechnology. I. Single-step, large-scale purification method for cytochrome P450 BM-3 by anion-exchange chromatography. J Chromatogr A 848: 149-159

Schwaneberg U, Schmidt-Dannert C, Schmitt J, Schmid RD (1999b) A continuous spectrophotometric assay for P450 BM-3, a fatty acid hydroxylating enzyme, and its mutant F87A. Anal Biochem 269: 359-366

Schwaneberg U, Appel D, Schmitt J, Schmid RD (2000) P450 in biotechnology: zinc driven omega-hydroxylation of p-nitrophenoxydodecanoic acid using P450 BM-3 F87A as a catalyst. J Biotechnol 84: 249-257

Schwaneberg U, Otey C, Cirino PC, Farinas E, Arnold FH (2001) Cost-effective whole-cell assay for laboratory evolution of hydroxylases in Escherichia coli. J Biomol Screen 6: 111-117

Seelbach K, Riebel B, Hummel W, Kula M-R, Tishkov VI, Egorov AM, Wandrey C, Kragl U (1996) A Novel, Efficient Regenerating Method of NADPH Using a New Formate Dehydrogenase. Tetrahedron Lett 37: 1377-1380

Sone T, Isobe M, Takabatake E, Ozawa N, Watabe T (1989) 7-ethenyloxycoumarin as a new substrate for fluorophotometric assay of hepatic microsomal epoxidizing activities. $\mathrm{J}$ Pharmacobiodyn 12: 149-158

Stevenson J-A, Westlake ACG, Whittock C, Wong L-L (1996) The Catalytic Oxidation of Linear and Branched Alkanes by Cytochrome P450cam. J. Am. Chem. Soc. 118: 1284612847

Taylor M, Lamb DC, Cannell RJ, Dawson MJ, Kelly SL (2000) Cofactor recycling with immobilized heterologous cytochrome P450 105D1 (CYP105D1). Biochem Biophys Res Commun 279: 708-711

Tischer W, Wedekind F (1999) Immobilized Enzymes: Methods and Applications. Top Curr Chem 200: 95-126

Tishkov VI, Galkin AG, Fedorchuk VV, Savitsky PA, Rojkova AM, Gieren H, Kula MR (1999) Pilot scale production and isolation of recombinant NAD+- and NADP+-specific formate dehydrogenases. Biotechnol Bioeng 64: 187-193

Tsotsou GE, Cass AE, Gilardi G (2002) High throughput assay for cytochrome P450 BM3 for screening libraries of substrates and combinatorial mutants. Biosens Bioelectron 17: 119131

Urlacher V, Schmid RD (2002) Biotransformations using prokaryotic P450 monooxygenases. Curr Opin Biotechnol 13: 557-564

Williams PA, Cosme J, Sridhar V, Johnson EF, McRee DE (2000a) Mammalian microsomal cytochrome P450 monooxygenase: structural adaptations for membrane binding and functional diversity. Mol Cell 5: 121-131

Williams PA, Cosme J, Sridhar V, Johnson EF, McRee DE (2000b) Microsomal cytochrome P450 2C5: comparison to microbial P450s and unique features. J Inorg Biochem 81: 183190

Woyski D, Cupp-Vickery JR (2001) Enhanced expression of cytochrome P450s from lacbased plasmids using lactose as the inducer. Arch Biochem Biophys 388: 276-280 
Yano JK, Blasco F, Li H, Schmid RD, Henne A, Poulos TL (2003) Preliminary characterization and crystal structure of a thermostable cytochrome P450 from Thermus thermophilus. J Biol Chem 278: 608-616

Zhang Z, Chouchane S, Magliozzo RS, Rusling JF (2002) Direct voltammetry and catalysis with Mycobacterium tuberculosis catalase-peroxidase, peroxidases, and catalase in lipid films. Anal Chem 74: 163-170 


\section{Figure legends}

Fig. 1 General hydroxylation reaction catalyzed by P450 monooxygenases in the presence of oxygen.

Fig. 2 Detailed hydroxylation mechanism for P450 enzymes. For details see text. The square represents the enzyme's heme.

Fig. 3. Artificial electron-transfer pathway from zinc dust to the P450 BM-3 using cobalt(III)sepulchrate as a mediator (Schwaneberg et al. 1999b).

Fig. 4 NADPH-regeneration system using a formate dehydrogenase (FDH) from Pseudomonas sp. 101coupled with the hydroxylation of $\beta$-ionone by P450 BM-3 mutant (Maurer et al. 2003). 
Figure 1:

$$
\mathrm{R}-\mathrm{H}+\mathrm{O}_{2}+2 \mathrm{e}^{-}+2 \mathrm{H}^{+} \stackrel{\mathrm{P} 450}{\longrightarrow} \mathrm{R}-\mathrm{OH}+\mathrm{H}_{2} \mathrm{O}
$$

Figure 2:
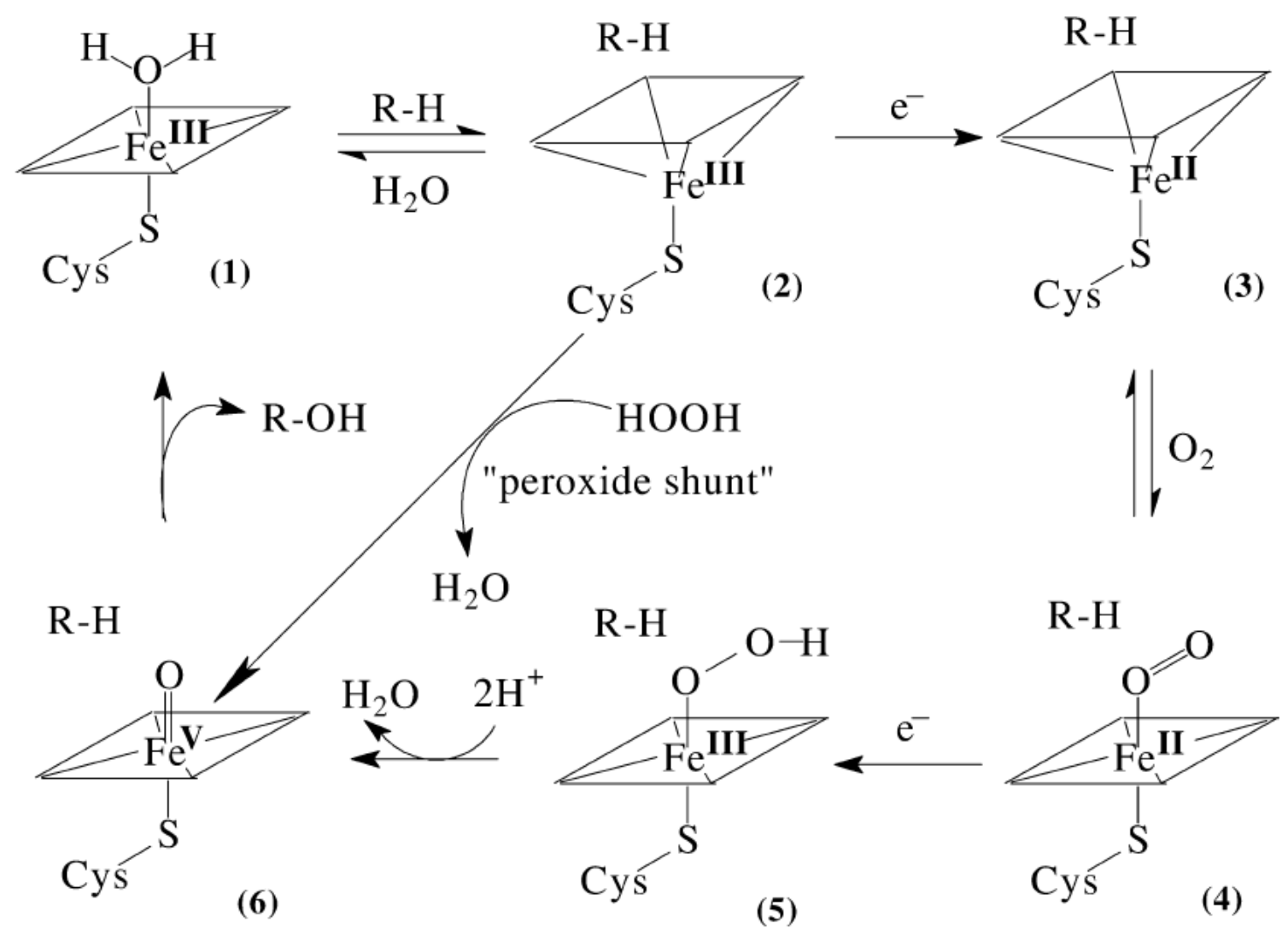

Figure 3:

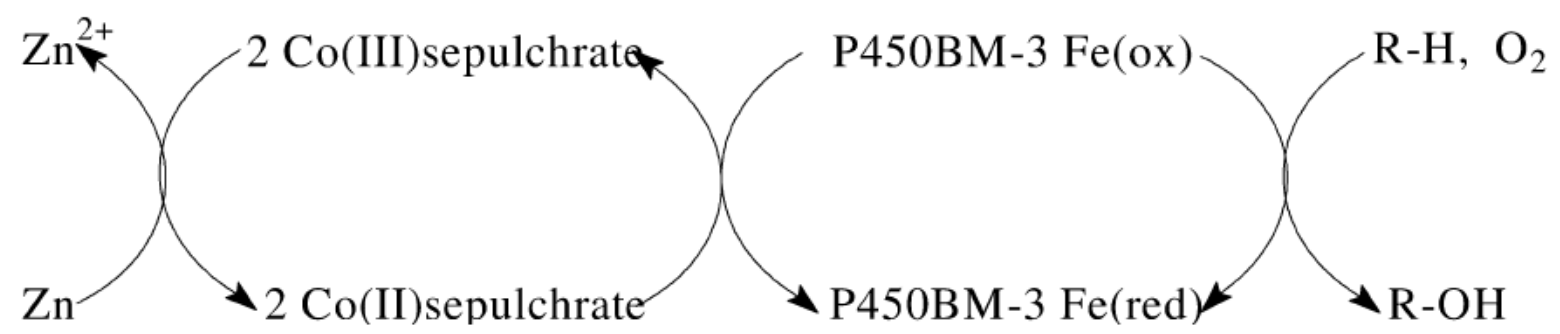


Figure 4:

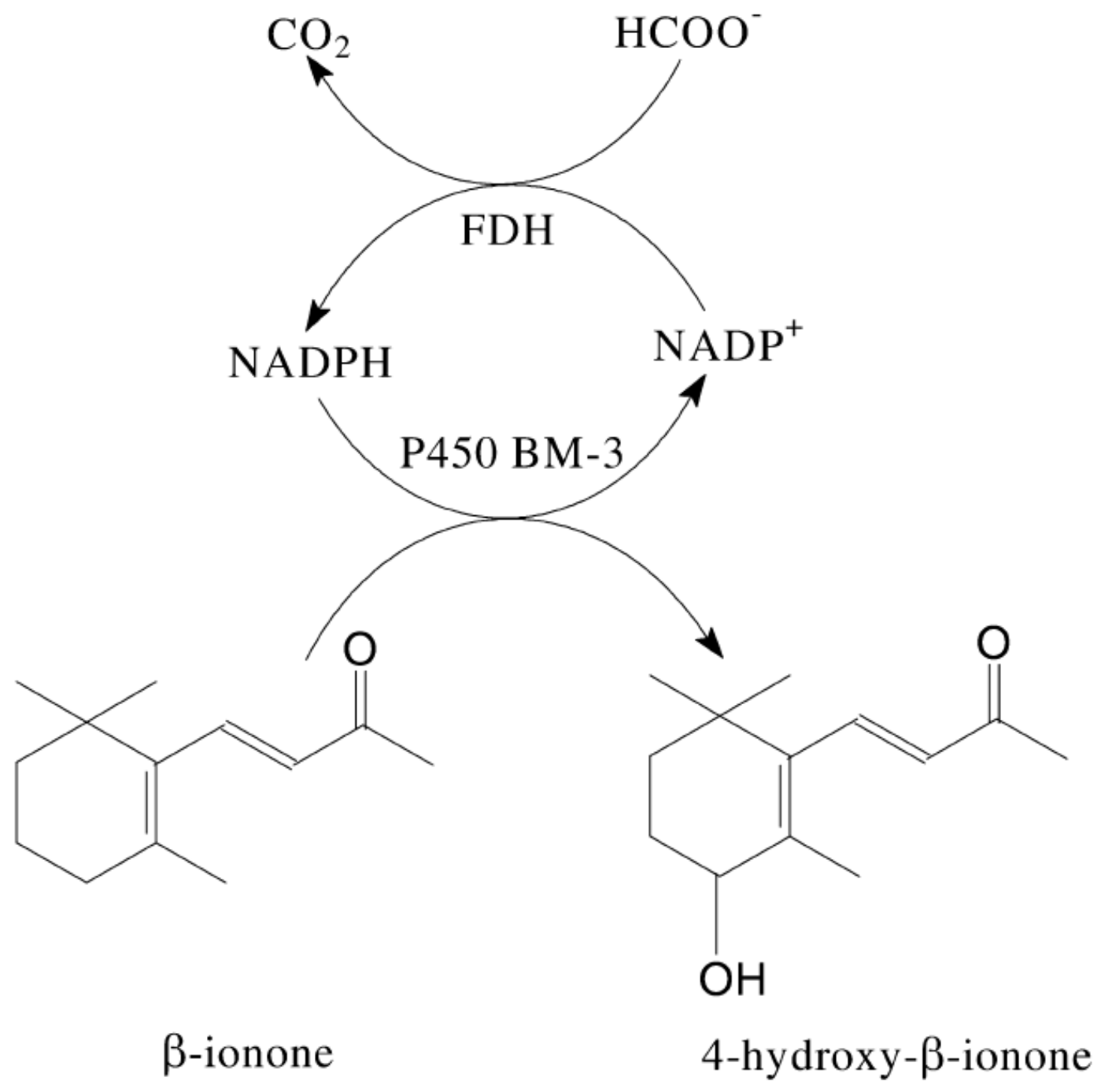

